\title{
Abnormal aortic valve echoes in mitral prolapse Echocardiographic features of floppy aortic valve
}

\author{
J CHRISTINE RODGER, PATRICIA MORLEY \\ From the Medical Unit, Monklands District General Hospital, Airdrie, Lanarkshire, and Department of Diagnostic \\ Radiology, Western Infirmary, Glasgow
}

SUMMARY The following distinctive combination of $M$-mode and two dimensional echocardiographic abnormalities of the aortic valve was observed in a group of 12 patients, of whom 11 had mitral valve prolapse. On two dimensional scans, the aortic cusps were freely mobile but appeared thickened or folded. On M-mode records, cusp excursion was normal: there was well defined systolic oscillation, and cusp echoes were multiple and centrally positioned within the aortic root during diastole.

The aortic valve was inspected at operation in two patients: a typically myxomatous valve was replaced in one and findings were in keeping with this diagnosis in the other. It is suggested that the echocardiographic features described are characteristic of the floppy aortic valve.

Despite the echocardiographic abnormalities, only three patients had clinical evidence of an aortic valve lesion. It is, therefore, further suggested that the investigation of patients with mitral prolapse should include echocardiographic assessment of the aortic valve, even when associated myxomatous degeneration of that valve is not suspected clinically.

This paper describes a distinctive combination of $M$-mode and two dimensional echocardiographic abnormalities seen in a group of patients with mitral valve prolapse. It is suggested that these echocardiographic abnormalities are characteristic of the floppy aortic valve.

\section{Patients}

Twelve patients (Table) were noted to have a distinctive combination of $M$-mode and two dimensional echocardiographic abnormalities of the aortic valve. The patients (nine men: three women) presented over a five year period: their ages at presentation ranged from 15 to 72 (mean 49 ) years. There was auscultatory evidence of mitral regurgitation in nine patients, of both mitral and aortic regurgitation in two, and of isolated aortic regurgitation in one. No patient had previous or current infective endocarditis. None was judged to have the clinical features of Marfan's syndrome but two did have congenital scoliosis of the thoracic spine.

Partly presented at the Annual General Meeting of the British Cardiac Society, Southampton April 1979:

Accepted for publication 22 December 1981
Three patients (cases 1, 2, and 3) underwent cardiac catheterisation: all were found to have severe mitral regurgitation. None had an aortic systolic gradient. Angiographic assessment of the aortic valve was omitted in case 1: modest aortic regurgitation was demonstrated in case 2 and there was no evidence of aortic regurgitation in case 3 . These three patients proceeded to operation and a typically floppy mitral valve was replaced in each.

Though it had not been suspected clinically, significant aortic regurgitation was found at operation in case 1 . The aortic root was dilated and the aortic valve was tricuspid. The cusps were thin and voluminous and the right coronary cusp was fenestrated in several places: the appearances were considered typical of myxomatous degeneration and the valve was replaced. In case 2 , the aortic root was of normal size and the valve was tricuspid: rolling of the edges of each commissure was reported but as the cusps appeared to meet adequately in the mid-line, the valve was not replaced. Inspection of the aortic valve was omitted in case 3.

\section{Methods}

M-mode echocardiograms were recorded with a 
Table Patients, auscultatory findings, and results of $M$-mode echocardiography

\begin{tabular}{|c|c|c|c|c|c|c|c|c|c|}
\hline \multirow[t]{3}{*}{ Case No. } & \multirow[t]{3}{*}{ Age/Sex } & \multirow[t]{3}{*}{ Murmurs } & \multicolumn{6}{|c|}{ M-mode echocardiogram } & \multirow[t]{3}{*}{ Comments } \\
\hline & & & \multirow{2}{*}{$\begin{array}{l}\text { Aortic } \\
\text { root }(\mathrm{cm})\end{array}$} & \multicolumn{2}{|c|}{ Aortic valve } & \multirow{2}{*}{$\begin{array}{l}\text { Mitral } \\
\text { prolapse }\end{array}$} & \multirow{2}{*}{$\begin{array}{l}\text { Left } \\
\text { atrium }(\mathrm{cm})\end{array}$} & \multirow{2}{*}{$\begin{array}{l}\text { Fractional } \\
\text { shortening \% }\end{array}$} & \\
\hline & & & & $\begin{array}{l}\text { Systolic } \\
\text { oscillation }\end{array}$ & $\begin{array}{l}\text { Diastolic } \\
\text { echoes }\end{array}$ & & & & \\
\hline $\begin{array}{r}1 \\
2 \\
3 \\
4 \\
5 \\
6 \\
7 \\
8 \\
9 \\
10 \\
11 \\
12\end{array}$ & $\begin{array}{l}57 \mathrm{M} \\
55 \mathrm{~F} \\
55 \mathrm{M} \\
69 \mathrm{M} \\
65 \mathrm{~F} \\
66 \mathrm{M} \\
63 \mathrm{M} \\
17 \mathrm{M} \\
72 \mathrm{M} \\
23 \mathrm{M} \\
15 \mathrm{M} \\
34 \mathrm{~F}\end{array}$ & $\begin{array}{l}\text { MR } \\
\text { MR, AR } \\
\text { MR } \\
\text { MR } \\
\text { AR } \\
\text { MR, AR } \\
\text { MR } \\
\text { MR } \\
\text { MR } \\
\text { MR } \\
\text { MR } \\
\text { MR }\end{array}$ & $\begin{array}{l}4 \cdot 8 \\
2.7 \\
3.2 \\
4.9 \\
3.3 \\
3.4 \\
3.2 \\
4.2 \\
3.0 \\
3 \cdot 1 \\
2.7 \\
3.3\end{array}$ & $\begin{array}{l}++ \\
+ \\
+++ \\
++ \\
+++ \\
++ \\
++ \\
+++ \\
+++ \\
++ \\
++ \\
++\end{array}$ & $\begin{array}{l}+++ \\
+++ \\
++ \\
++ \\
++ \\
++ \\
++ \\
+++ \\
++ \\
+++ \\
++ \\
++\end{array}$ & $\begin{array}{l}+ \\
+ \\
+ \\
+ \\
+ \\
+ \\
+ \\
+ \\
+ \\
+ \\
+ \\
+\end{array}$ & $\begin{array}{l}4.8 \\
5.5 \\
4.7 \\
4.7 \\
3.5 \\
2.0 \\
4.2 \\
2.1 \\
4.8 \\
2.0 \\
2.3 \\
2.2\end{array}$ & $\begin{array}{l}23 \\
29 \\
23 \\
23 \\
41 \\
48 \\
31 \\
34 \\
34 \\
29 \\
32 \\
43\end{array}$ & $\begin{array}{l}\text { MVR, AVR } \\
\text { MVR } \\
\text { Scoliosis, MVR }\end{array}$ \\
\hline
\end{tabular}

MR, mitral regurgitation; AR, aortic regurgitation; MVR, mitral valve replacement; AVR, aortic valve replacement; WPW, Wolff-ParkinsonWhite syndrome.

2.25 $\mathrm{MHz}$ transducer and either a Picker Echoview $80 \mathrm{C}$ or a Smith-Kline Eskoline 20 ultrasound system interfaced with a Honeywell strip chart recorder. In making measurements from the $M$-mode echograms, the criteria recommended by the American Society of Echocardiography ${ }^{1}$ were followed. The aortic root and the left atrium were judged to be dilated when their echocardiographic dimensions exceeded $3.7 \mathrm{~cm}$ and $4.0 \mathrm{~cm}$, respectively. ${ }^{2}$ The lower limit of normal for fractional shortening of the echocardiographic dimension of the left ventricle was taken as $28 \%{ }^{3}$

In case 1 , two dimensional echocardiograms were obtained with a linear array (Organon Teknika Echocardiovisor) and only long axis imaging was feasible. In the remaining patients, both the long and short axes were imaged, using either a prototype or a commercially available (Varian V3000) phased array. The images were recorded on viedotape. Figs. 1, 2, and 3 were photographed from the videotape replay and Fig. 4 was photographed, at the time of examination, from the primary oscilloscope display. In all the illustrations, timing is indicated by the right hand edge of the electrocardiogram.

\section{Results}

\section{AORTIC ROOT AND AORTIC VALVE}

(a) M-mode echocardiography (Table and Fig. 5, 6, 7, 8) Four patients had a dilated aortic root. Aortic cusp echoes appeared slightly thickened: they separated widely in systole and in six patients, three cusps were defined (Fig. 8). Pronounced systolic oscillation (Fig. 5, 6,7) was a constant feature: it was very gross in some instances (Fig. 8). In diastole, cusp echoes were multiple and centrally positioned within the aortic root (Fig. 5, 6, 8). There was no evidence of prolapse of cusp tissue into the left ventricular outflow tract. (b) Two dimensional echocardiography (Fig. 1,2,3,4) Bright echoes were recorded from the aortic cusps and these appeared thickened or folded. On long axis views, cusp mobility was seen to be unrestricted and systolic oscillation of the free edge of the leaflets was observed. Prolapse of cusp tissue into the left ventricular outflow tract was suspected in two patients. Short axis imaging defined three aortic cusps (Fig. 3) in the 11 patients examined. Apparent thickening or folding of the leaflets was most obvious when the valve was closed (Fig. 3a, 4c): systolic separation was wide and the valve orifice was unobstructed (Fig. 1b, $3 b, 4 b)$.

\section{MITRAL VALVE (Table)}

Eleven patients had classical M-mode evidence of mitral valve prolapse; diastolic excursion of the mitral anterior leaflet was increased and systolic sagging of the leaflets extended from 3 to $10 \mathrm{~mm}$ behind the $C$ point of the mitral echogram. A partially flail posterior leaflet was suspected in case 9 (Fig. 7). Long axis two dimensional imaging in these patients was consistent with mitral prolapse.

The remaining patient (case 5) also had a nonrheumatic mitral valve (Fig. 4): mild mitral prolapse was thought to be possible but unequivocal diagnostic features were lacking.

\section{LEFT ATRIUM (Table)}

The left atrium was dilated in six patients, including the three who were operated on.

LEFT VENTRICLE (Table)

Fractional shortening of the echocardiographic dimension of the left ventricle was reduced in three patients, including two of those operated on. 
Fig. 1 Two dimensional echocardiograms (case 2, after mitral valve replacement): (a) Long axis, diastole. (b) Short axis, early systole. The right (RCC) and non-coronary (NCC) cusps have been identified in both views. The non-coronary cusp appears thickened or folded: the aortic valve orifice is unobstructed. On the real-time display, vigorous systolic oscillation of the right coronary cusp was seen in the long axis view. IVS, interventricular septum; MP, mitral prosthesis; LA, left atrium; TV, tricuspid valve; $P V$, pulmonary valve.

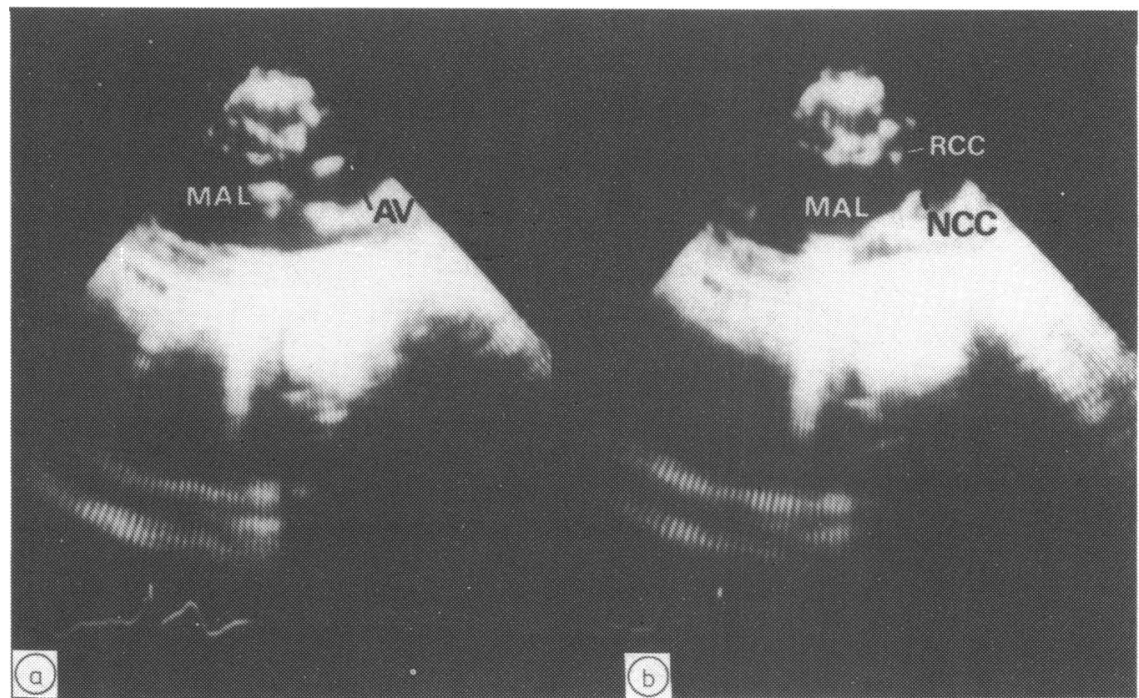

Fig. 2 Long axis two dimensional echocardiograms (case 8) in (a) diastole and (b) early systole. The aortic cusps appear thickened: diastolic apposition is normal. Systolic oscillation of both cusps was seen on the real-time display. The mitral anterior leaflet appears thickened and elongated. $A V$, aortic valve, $M A L$, mitral anterior leaflet. 


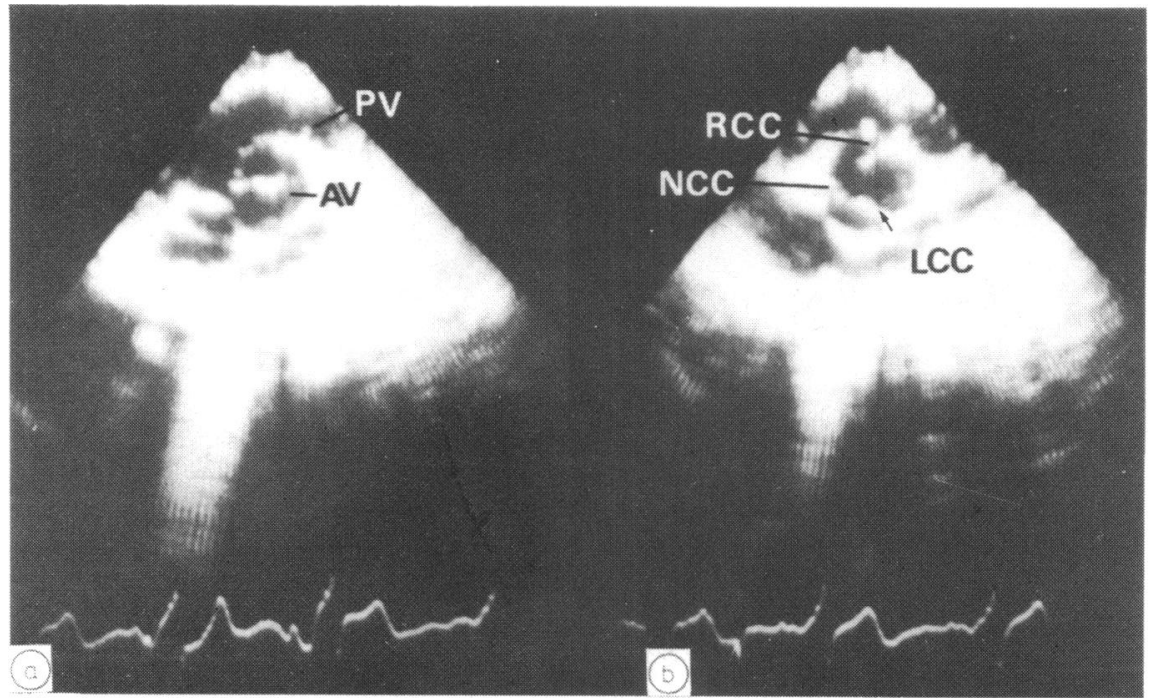

Fig. 3 Short axis two dimensional echocardiograms (case 8) at (a) end-diastole and (b) late systole. The closed aortic valve appears thick. In the open position, three cusps are seen: all look thickened or folded but an adequate aortic orifice is maintained. LCC, left coronary cusp.

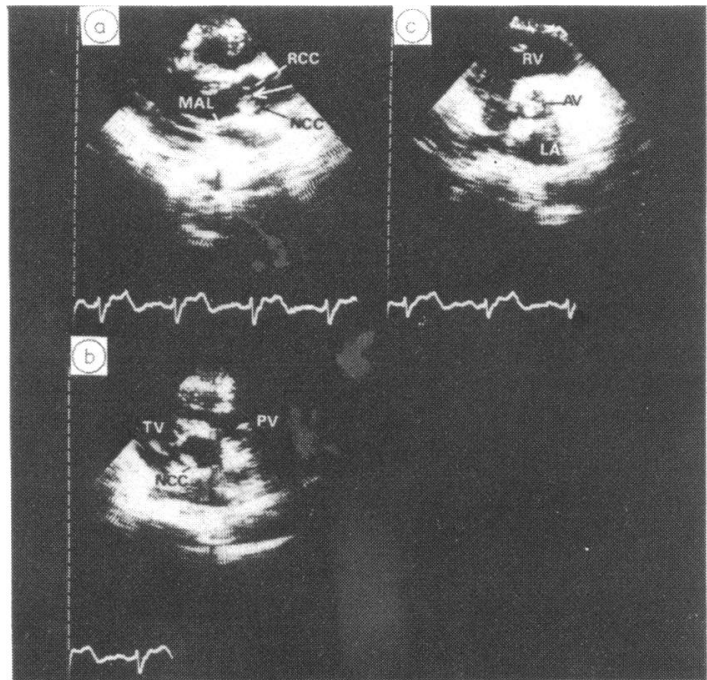

Fig. 4 Two dimensional echocardiograms (case 5). (a) Long axis, systole. (b) Short axis, late systole. (c) Short axis, early systole. The closed aortic valve appears thickened (c). In the open position, thickening or folding appears particularly to involve the non-coronary cusp: the aortic orifice is unobstructed. The structure arrowed in (a) is probably the left coronary cusp.

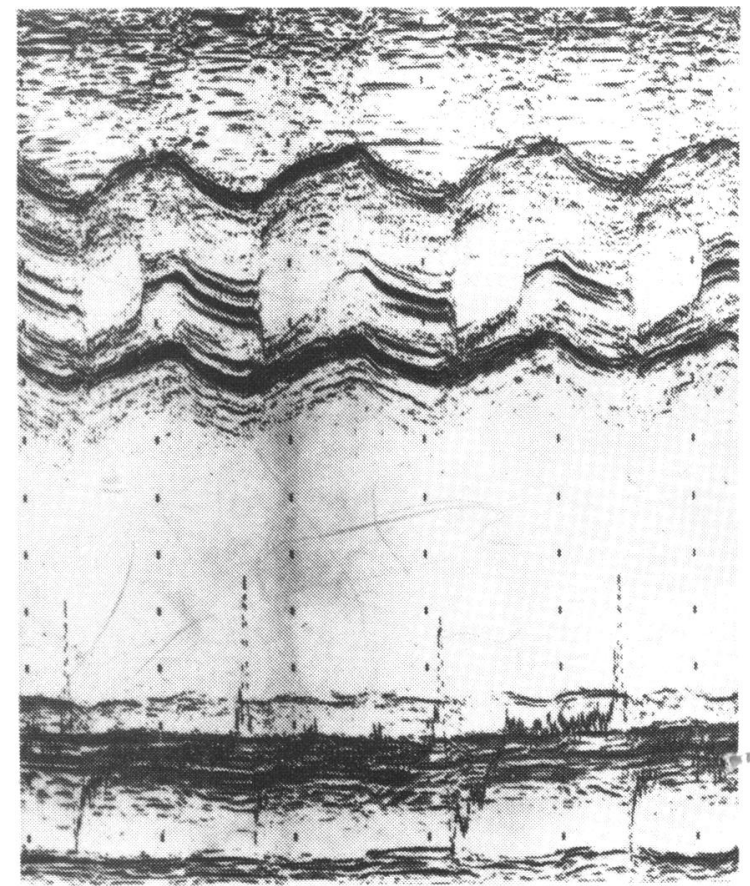

Fig. $5 M$-mode echocardiogram of aortic valve (case 2, after mitral valve replacement). Systolic excursion of the cusps is normal: there is fine systolic oscillation. Cusp echoes are multiple and centrally positioned throughout diastole. 


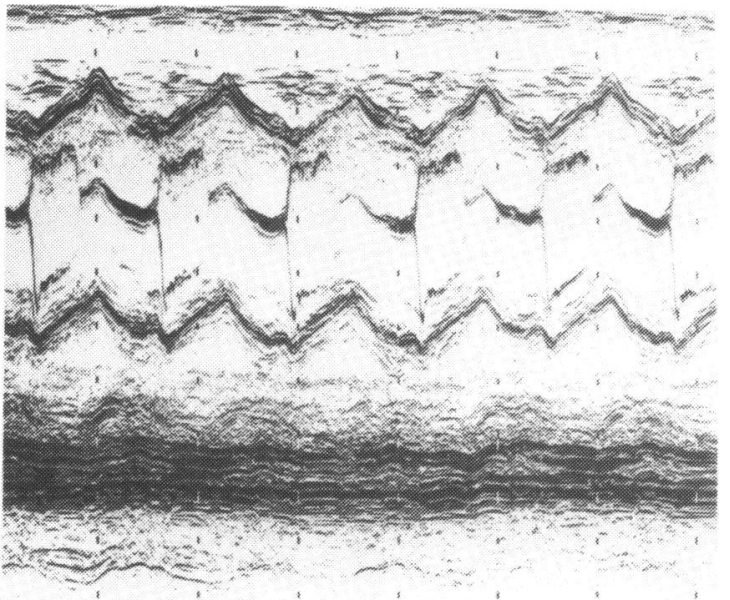

\section{Discussion}

Our patients were selected on the basis of a distinctive combination of echocardiographic abnormalities of the aortic valve. All but one of them was found also to have classical echocardiographic evidence ${ }^{4}$ of mitral valve prolapse and a typically floppy mitral valve was shown in the three who were operated on. One of our patients (case 1) undoubtedly had a floppy aortic valve and operative findings were in keeping with this diagnosis in another (case 2). As it is established that myxomatous degeneration of the mitral valve may, on occasion, be associated with myxomatous degeneration of the aortic valve, ${ }^{6-9}$ it is not unreasonable to speculate that the remaining patients also had floppy aortic valves.

On the two dimensional scans, the aortic cusps looked thick and, on static images, could easily have been thought to be calcified. Viewed in movie format, however, they were clearly freely mobile and there was oscillation of their free edges. M-mode records confirmed the mobility and the systolic oscillation and showed that, at most, there was only minimal thickening of the free edges of the leaflets. Thus, despite the two dimensional appearances, the cusps were obviously not in fact thick, and we suggest that folding of

Fig. $6 M$-mode echocardiogram (case 8). The aortic root is dilated. Systolic excursion of the cusps is normal. There is welldefined systolic oscillation of both cusps. Cusp echoes are multiple in mid and late diastole and centrally positioned throughout diastole.

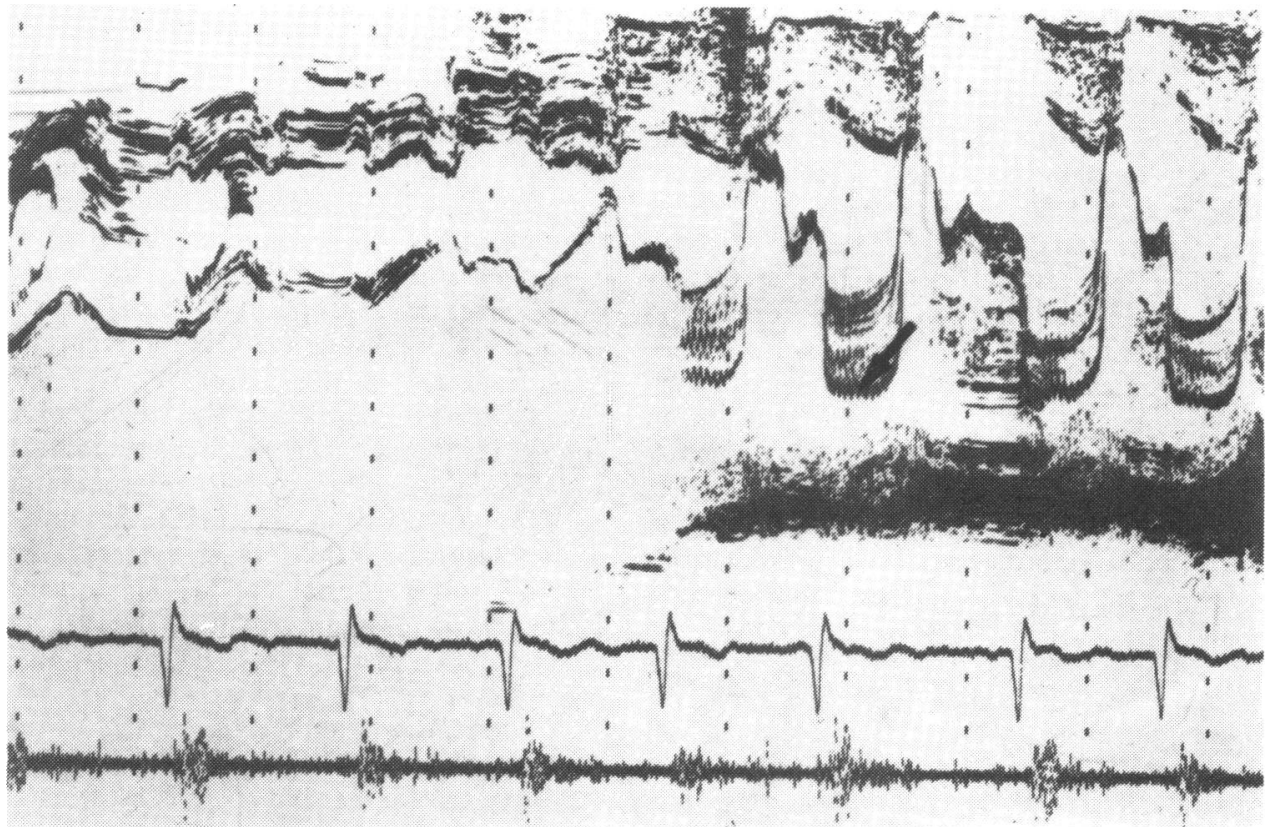

Fig. 7 Phonocardiogram and M-mode sweep from aorta to mitral valve (case 9). Systolic excursion of the aortic cusps is normal: there is systolic oscillation of the non-coronary cusp and apparent thickening of the right coronary cusp. In diastole, aortic cusp echoes are multiple and anteriorly displaced. Diastolic excursion of the mitral anterior leaflet is increased. There is pansystolic sagging of the mitral echogram: systolic vibration (arrowed) suggests that the valve is partially flail. 


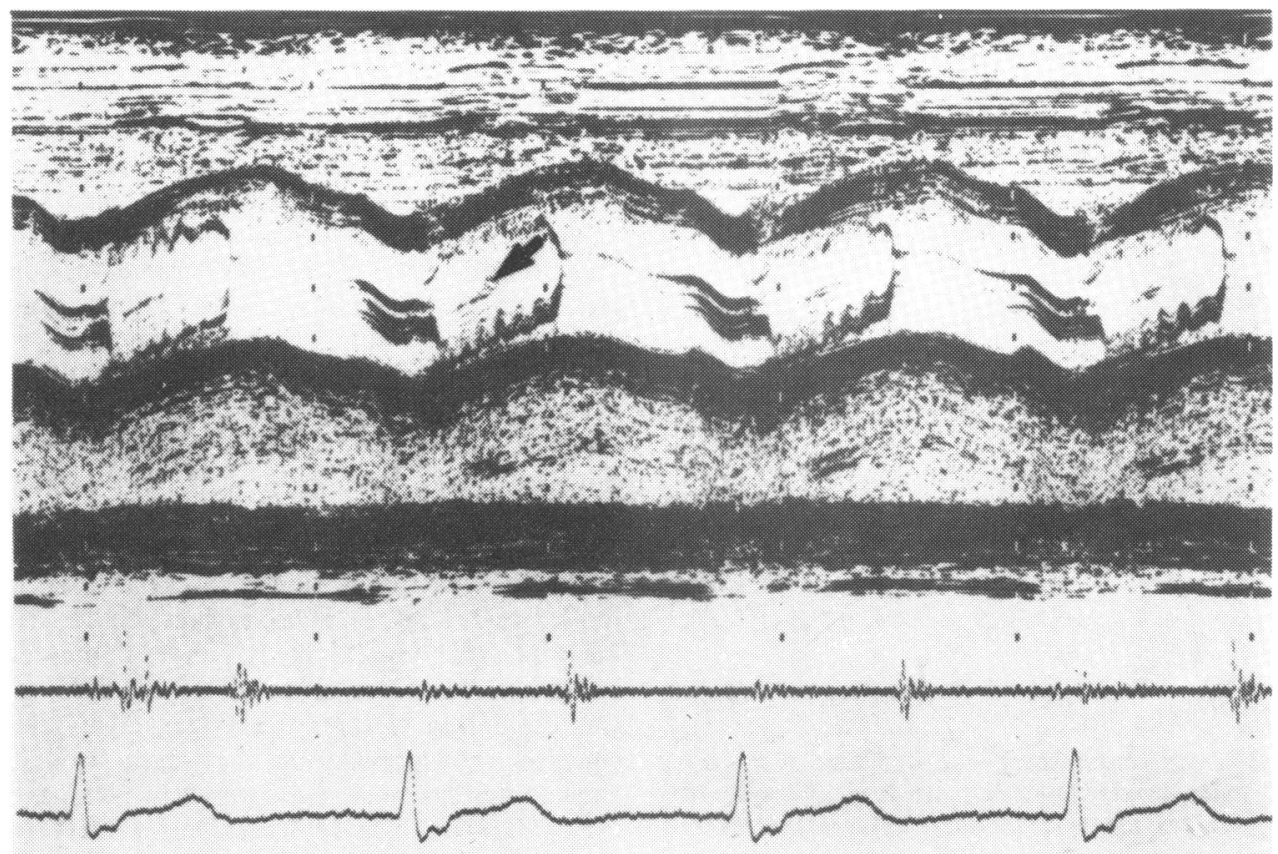

Fig. 8 M-mode echocardiogram and phonocardiogram from the patient with an isolated aortic diastolic murmur (case 5). Echoes have been recorded from all three aortic cusps (the left coronary cusp is arrowed). Cusp excursion is normal: there is coarse systolic oscillation. Cusp echoes are multiple in mid and late diastole and centrally positioned throughout diastole.

redundant cusp tissue could account for the apparent thickening of the two dimensional images and for the multiple diastolic echoes on the M-mode records.

We have proof of a floppy aortic valve in a patient with mobile but apparently thickened aortic cusps on two dimensional images and with systolic oscillation of the cusps and multiple diastolic cusp echoes on the aortic M-mode echogram. We suggest that this combination of $M$-mode and two dimensional echocardiographic abnormalities, which has not been described previously, is characteristic of the floppy aortic valve.

It must be stressed that it is the combination of echocardiographic abnormalities which we regard as characteristic of the floppy aortic valve: considered in isolation, some of the features could be otherwise explained. Thus, systolic oscillation of the aortic valve (without apparent thickening) is a non-specific finding, and both calcified ${ }^{10}$ and bicuspid ${ }^{11}$ aortic valves have echocardiographic features similar to some but not to all of those recorded in our patients.

There have been no previous decriptions of the two dimensional echocardiogram recorded from a floppy aortic valve and little has been written about the M-mode findings. Chandraratna et al.'s account ${ }^{12}$ of diastolic fluttering and diastolic separation of the cusp echoes in a patient with a non-infected, regurgitant, myxomatous aortic valve is at variance with the present $M$-mode findings. This report, however, also noted systolic oscillation and Chandraratna suggested that multiple diastolic echoes might be recorded from a single redundant cusp, giving the appearance of cusp separation. Rippe et $a l .{ }^{13}$ recorded M-mode echograms in four patients with regurgitant myxomatous aortic valves. Three of their patients had dilatation of the aorta and the valve looked normal though its excursion was small in relation to the aortic root. More in keeping with the present observations, they mentioned (but did not describe) additional abnormal aortic echoes which were present in two patients and were thought possibly to reflect leaflet redundancy. In another patient, high frequency systolic vibration of the aortic cusps was noted without comment.

Aortic regurgitation is a recognised feature of Mar. fan's syndrome. It is often attributed solely to dilatation of the aortic root but there is evidence that myxomatous degeneration of the aortic valve may be an additional causal factor. ${ }^{14}$ With this in mind, it is interesting to note the $M$-mode features which we have ascribed to the floppy aortic valve, in the published echograms of patients who had Marfan's syn- 
drome with dilatation of the aortic root and mitral prolapse. ${ }^{15} 16$

Thus, careful scrutiny of previous reports provides evidence to support our contention that the M-mode features which we have described are characteristic of the floppy aortic valve. In our $M$-mode examinations we took care always to record maximal separation of the aortic cusps and to note any changes which occurred with slight alterations in the direction of the ultrasound beam. It is possible that previous workers did not do so and this may explain why they did not consistently observe the M-mode features described here.

An aortic valve lesion was suspected clinically in only three of our patients. As there are no known characteristic auscultatory features, floppy aortic valves are likely to be recognised clinically only when they become infected or when they become spontaneously regurgitant. Thus, though there have been studies of surgical and necropsy material, ${ }^{917}$ the true incidence of myxomatous degeneration of the aortic valve is at present unknown. It appears from the present study that echocardiographic surveys might provide the information.

Further validation is necessary, but we suggest that the combination of $\mathrm{M}$-mode and two dimensional echocardiographic abnormalities which we have described can be regarded as diagnostic of a floppy aortic valve. We recommend that the investigation of patients with mitral prolapse should inciude echocardiographic assessment of the aortic valve even when associated myxomatous degeneration of that valve is not suspected clinically.

\section{References}

1 Sahn DJ, De Maria A, Kisslo J, Weyman A. Recommendations regarding quantitation in M-mode echocardiography: results of a survey of echocardiographic measurements. Circulation 1978; 58: 1072-83.

2 Feigenbaum H. Echocardiography. In: Braunwald E, ed. Heart disease. Philadelphia, London, Toronto: W B Saunders, 1980: 96-146.

3 Karliner JS. Clinical reliability of determining left ventricular function by echocardiography. In: Kotler MN, Segal BL, eds. Clinical echocardiography. Philadelphia: F A Davis, 1978: 151-65.
4 De Maria AN, King JF, Bogren HG, Lies JE, Mason DT. The variable spectrum of echocardiographic manifestations of the mitral valve prolapse syndrome. Circulation 1974; 50: 33-41.

5 Markiewicz W, Stoner J, London E, Hunt SA, Popp RL. Mitral valve prolapse in 100 presumably healthy young females. Circulation 1976; 53: 464-73.

6 Read RC, Thal AP. Surgical experience with symptomatic myxomatous valvular transformation (the floppy valve syndrome). Surgery 1966; 59: 173-82.

7 McKay R, Yacoub MH. Clinical and pathological findings in patients with "floppy" valves treated surgically. Circulation 1973; 47, suppl III: 63-73.

8 Davies MJ, Moore BP, Braimbridge MV. The floppy mitral valve: study of incidence, pathology, and complications in surgical, necropsy, and forensic material. $\mathrm{Br}$ Heart f 1978; 40: 468-81.

9 Rippe JM, Angoff G, Sloss LJ, Wynne J, Alpert JS. Multiple floppy valves: an echocardiographic syndrome. Am f Med 1979; 66: 817-24.

10 Gramiak R, Shah PM. Echocardiography of the normal and diseased aortic valve. Radiology 1970; 96: 1-8.

11 Nanda NC, Gramiak R, Manning J, Mahoney EB, Lipchik EO, DeWeese JA. Echocardiographic recognition of the congenital biscupid aortic valve. Circulation 1974; 49: 870-5.

12 Chandraratna PAN, Samet P, Robinson MJ, Byrd C. Echocardiography of the "floppy" aortic valve: report of a case. Circulation 1975; 52: 959-62.

13 Rippe J, Fishbein MC, Carabello B, et al. Primary myxomatous degeneration of cardiac valves: clinical, pathological, haemodynamic, and echocardiographic profile. Br Heart $\mathcal{F}$ 1980; 44: 621-9.

14 Read RC, Thal AP, Wendt VE. Symptomatic valvular myxomatous transformation (the floppy valve syndrome): a possible forme fruste of the Marfan syndrome. Circulation 1965; 32: 897-910.

15 Winsberg F. Aortic valve. In: Gramiak R, Waag RC, eds. Cardiac ultrasound. Saint Louis: C V Mosby, 1975: 74-90.

16 Rinke H. Echocardiographic examination of the aortic root and aortic valve. In: Bom N, ed. Echocardiology with Doppler applications and real time imaging. The Hague: Martinus Nijhoff, 1977: 23-39.

17 Olsen EGJ, Al-Rufaie HK. The floppy mitral valve: study on pathogenesis. Br Heart $\mathcal{f}$ 1980; 44: 674-83.

Requests for reprints to Dr J C Rodger, Monklands District General Hospital, Airdrie, Lanarkshire ML6 0JS. 